\title{
Project managers' Knowledge Sharing Supported by Technology: the Case of Microsoft Teams
}

\author{
Viktoria Eriksson, Department of Informatics, Linnaeus University, Sweden \\ Niki Chatzipanagiotou, Department of Informatics, Linnaeus University, Sweden
}

\begin{abstract}
Contemporary organizations frequently employ projects to leverage work across organizational units, utilizing specialized knowledge from different areas of the organization to meet specific quality criteria in a defined time period, at a set cost. Project managers act as hubs of knowledge in directing projects and driving their success, often using technology for this purpose. To date, little is known in how far technology support this knowledge sharing in the project management.

The paper aims to explore project managers' perceptions regarding their knowledge sharing and how this is supported by recent technology. The paper further explores benefits and challenges experienced by project managers when using the specific technology for their knowledge sharing. The research adopts the interpretive qualitative approach and collects data through semi-structured interviews with project managers using such a technology. 3 C's analysis was used to analyze the collected empirical material to generate 6 concepts. The concepts are then reviewed in context of selected theoretical framework, including the informatics domain model by Beynon-Davies. The findings indicate that the technology largely supports knowledge sharing of project managers, both presenting opportunities for more efficiency as well as new challenges. The technology leads to change in the modus of knowledge sharing and also individuals' approach: what, when and how knowledge is shared.

This enhanced understanding contributes to existing theory and the insights can aid practitioners in development or introduction of technology in the workplace. The work also contributes to theory about how project managers can leverage knowledge across projects with the aid of such a technology as well as to project managers' and managers' work, such as to make efficient use of a technology and avoid certain challenges.
\end{abstract}

\section{Introduction}

Information systems and technology connect people across the globe impacting business and personal lives through the ability to share knowledge with ease and at an unprecedented speed in an increasingly digital world. We have become a population that works to generate and share knowledge and the associated changes in the information systems "stimulate economic development and create opportunities for social and economic change" (Petter, Delone and McLean, 2012).

Knowledge and sharing of knowledge have an extensive research tradition and its grounding lies in philosophy, with the definition of knowledge. The seminal work of Polanyi (1966) defined tacit knowing as knowledge arising by integration that is highly dependent on its context, in contrast to explicit knowledge which is readily transmitted by coding. Tacit (subjective) knowledge involves human process and cannot readily be quantified, but it can be externalized (into explicit and objective knowledge) by an individual and thus can be shared within an organization (Ichijō and Nonaka, 2007).

Project management is a key methodology in the workplace of matrix organizations, also referred to as "project management is the work of the 21st Century" by Kogon et al. (2015), and the PMI argues that projects leverage change and "get [s] work done" (PMI, 2020). It is a defined set of work carried out over a defined time period that results in a unique product, where the product can be anything such as a physical good, technology or a new method of doing something according to defined criteria (cost, quality and duration) (Wells and Kloppenborg, 2015).

Project managers' daily work involves sharing knowledge with multiple stakeholders from different organizational departments, subject matter backgrounds and of different organizational hierarchy; a project manager regularly shares knowledge within and beyond their team. In fact, there is a growing tendency to consider knowledge as important throughout the complete life cycle of projects and knowledge management has been 
identified as a key success factor for project success (Fuentes-Ardeo, Otegi-Olaso and Aguilar-Fernandez, 2017). This paper concerns knowledge sharing within the profession, such as new knowledge gained e.g. in case of a research project, or about the project management process itself, e.g. aspects often captured in a so called "lesson's learned" (Project Management Institute, 2013).

Previous related studies about knowledge sharing of this professionals' group (Kauffmann and Carmi, 2008; Stray, Moe and Noroozi, 2019; Wolf and Blomberg, 2020) show that there are challenges when it comes to technologymediated knowledge sharing and communication within teams, such as that enabled by Slack; there are differences on the way people make sense of technology and, therefore, understand their work practices; and the usefulness of a technology is affected by the context of use.

Accordingly, the research problem relates to in how far and how well the above types of knowledge sharing are supported by a recent technology, where Microsoft Teams (MS Teams) serves as an example (a case). To date there are no similar studies of how MS Teams is used in project management team members' knowledge sharing. Microsoft (MS) Teams is a recent, multi-device technology referred to as a chat-based workspace that supports knowledge sharing through provision of a range of functionalities, e.g. remote meeting functionality, chat, file sharing and file collaboration by joint editing (Microsoft, 2019). It makes use of cloud technology, is part of the Office 365 suite and is thus part of an application (app) landscape where supporting apps may provide additional knowledge sharing and knowledge management functionality. For purpose of delimitation, the standard set up of MS Teams is considered: the chat workspace, file sharing (SharePoint), note taking (OneNote), planner as well as call and meetings. Additional applications (apps) beyond the standard default set up are not in focus (Microsoft, 2020).

The research setting is that of two large matrix organizations located in Germany. Projects in the organizations' target departments often include upstream research with a significant amount of knowledge management and they often span several different sites and so the project management process heavily relies on technology. MS Teams was introduced over the last two years but at the time of research, it remained the individual's or individual teams' choice in determining the extent of their use of MS Teams. At the time, it remained unclear how it is being used and to what extent the options within MS Teams supports or perhaps even overwhelms an individual user in their task to collaborate in projects. So, this paper aims to explore and interpret the project managers' perceptions regarding their knowledge sharing and how this is supported by a technology. Furthermore, the research explores the benefits and challenges that project managers experience when using the specific technology for knowledge sharing.

The paper is structured as follows. Following this introduction, the paper continues with section two, a brief literature review and the theoretical framework used in the research. Section three describes the paradigm, methodology, and the methods of data collection and data analysis process. The findings are presented in section four along with a discussion. The paper concludes with section five which presents the conclusions of this research.

\section{Literature and Theoretical Framework}

Existing literature within the field of informatics and project management was reviewed to outline related concepts and support the research. The literature review formed the theoretical basis of this work by presenting the main concepts of knowledge sharing, technology that supports knowledge sharing and project management. The theory of the Informatics Domain Model, which is adopted from Beynon-Davies (2013), supports the theoretical framework of this research.

Knowledge inherently includes human values and ideals, which are subjective, and along with the context influences what may be considered as true knowledge (Ichijō and Nonaka, 2007). The seminal work of the SECI model (short for the following modes of knowledge conversion: socialization, externalization, combination, internalization) of knowledge dimensions explains how tacit and explicit knowledge gets transformed into knowledge that benefits an organization (they become organizational knowledge), by the processes outlined in the SECI model (Ichijō and Nonaka, 2007). In the SECI model, dialogues and practice gets their direction and energy from a knowledge vision and a set of driving objectives for knowledge generation in the organization, the knowledge assets are the entities that form in- and outputs of the SECI process, within an ecosystem of knowledge called the environment. The dialogues is the exchange between individuals, merging their knowledge, and the practice is for sharing tacit knowledge; together they enable the knowledge growth from subjective views (Ichijo and Nonaka, 2007). Ba is a Japanese concept of a (physical) place, but in this setting rather a conceptual place of a shared context that is developed over time; the ongoing growth of knowledge. Accordingly, Ba needs to be built, maintained and connected whether through a physical or mental space (Ichijō and Nonaka, 2007).

Research into knowledge sharing in organizations has determined several factors that impact knowledge sharing, such as a reluctance to sharing because of a consideration of knowledge as a private good (McLure Wasko and 
Faraj, 2000), outcomes (goals and rewards), means (task and resources at hand) and relationships (sense of identity, friendship and proximity). However, Ghobadi and Mathiassen (2016) argue that simply taking concerns seriously and addressing these openly can enhance knowledge sharing. Yet, knowledge sharing within remote work, whether fully or in part, can lead to employees sharing less knowledge (van der Meulen et al., 2019). Though van der Meulen et al. (2019) hypothesize that technologies such as enterprise social media may boost the component which they consider critical, knowledge awareness: knowing who knows what in an organization.

Knowledge sharing may occur in many ways and when through the means of technology, this may include but not be limited to email, instant messaging, wiki-style entries, blogs, technology-enabled audio and or video calls, virtual whiteboards and file sharing. The work of Stray et al. (2019) shows that also the choice and way of using a technology is important in enhancing knowledge sharing. Technology that enable knowledge sharing can be divided into "communication and discourse systems" (e.g. video-conferencing, instant messaging) and "knowledge repository systems", where the latter refers to systems that store and enable access to knowledge artefacts (Massey and Montoya-Weiss, 2006). Yet, technology has also been identified as a potential barrier to knowledge sharing (Olaniran, 2017). Similarly, key individuals acting as mediators may be useful to establish technology within an organization, but can also establish sub-optimal use of technology (Bansler and Havn, 2006).

Several branches of project management exist, some focusing on a traditional methodology termed "waterfall" that championed by organizations such as PMI, International Project Management Association (IPMA), Prince2 (IPMA, 2020; APM, 2020; PRINCE2, 2020) and others. Agile project management is based on an iterative rather than linear (waterfall) process (Bredillet, 2014). For clarity, examples and discussions in this research refer to socalled waterfall project management and examples were drawn from PMI where possible. The project manager is concerned with a range of tasks and artefacts as part of their communication plan and execution: their structured approach to knowledge sharing within the project and the environment around it (the organization) (Project Management Institute, 2013). Similarly, new knowledge generated in projects need to be shared to the organization at the end of a project when the team is dispersed, to ensure that the knowledge is available beyond the project closure (Mueller, 2015). The inherent nature of projects structurally separates them from other ongoing work efforts which can have negative consequences for the organization's knowledge processes by preventing smooth knowledge sharing (Mueller, 2015). Furthermore, Morris (2013) argues that many projects involve elements of remote working, where participants are located in different geographical locations, possibly in different time zones. Where co-location of project members is considered ideal for project success, remote teams are on the other side of that spectrum since technology must be employed (Wells and Kloppenborg, 2015). Ultimately, projects often generate new knowledge and may be regarded as "repositories of knowledge", so when leveraging projects' knowledge, one can minimize work redundancy and mistakes (Wiewiora et al., 2014).

For project management, it has been demonstrated that teams decide and then adhere to specific technologies early on in the project life cycle (Gomes, Oliveira and Chaves, 2018). The authors also defined technologies relevant for project management: instant-messaging, office document software, project management tools, email, file sharing, tele-conferencing, video-conferencing, wikis and technical tools (e.g. for development and testing of software) (Gomes, Oliveira and Chaves, 2018). More recent research into project teams relying on technology demonstrated that teams with access to communication feeds in one location, and so benefited from an additional sense of awareness, enhanced their project performance (Krancher, Dibbern and Meyer, 2018). This was especially prominent during intensive periods of work over distributed teams, where the teamwork was improved due to the (technology enabled) awareness of ongoing exchange.

It is possible to consider the research problem in context of the informatics domain model from Beynon-Davies (2013) by assigning the relevant entities from the research problem to the components of the model, as it is presented in the discussion section. The model assumes that the effects of an information system (IS) upon an organization emerge over time as the product of the interaction between a system and its context within an organization (Beynon-Davies, 2013). The organization is the main context of an IS and is made up of distinct, but interdependent activity systems. When these act together, they generate value in the form of a product or service (Beynon-Davies, 2013). Equally, the organization can get value originating from its external environment in the form of inputs from suppliers and acting upon these generates other forms of value, making it a value-creating system. In turn, any activity system employs an IS. That is, a system that allows the individuals in that system to communicate and coordinate their actions, making it clear that information is critical to the effective functioning of an organization since decision for action is based on information (Beynon-Davies, 2013). The information system gets its information from an ICT system that processes business data, where information is data that has been interpreted in a way (so that it has a meaning) and a single datum is "one or more symbols used to represent something" (Beynon-Davies, 2013, p. 7). Accordingly, hardware, software, data and communication technology make up the ICT that supports as IS, ranging from improving operation in activity systems of an organization to actually improving activity systems between the organization and its external environment, the wider value network. The literature review and the informatics domain model formed the theoretical framework of this work and fed into the discussion of the research findings. 


\section{Methodology and Methods}

\section{Paradigm and Methodological Approach}

The research adopts the interpretive paradigm which reflects our interest in exploring the meanings and understandings people bring to their work activities. Interpretive research assumes a reality that is subjective, whereby the individuals in a specific social context (co-)construct the meanings that surround them (Hesse-Biber and Johnson, 2015) and seeks to understand the meanings people assign to a situation (Klein and Myers, 1999). In addition, interpretivism seeks to understand the context of a system, as well as how the system and context influence one another (Walsham, 1993; Klein and Myers, 1999). The interpretive paradigm is, then, considered suitable for exploring and interpreting the influence of a technology on project managers and their knowledge sharing work. The qualitative methodological approach is chosen because it is considered suitable for tackling multiple subjective perspectives and views of the participants, who are considered experts, to gain understanding of how a technology supports their knowledge sharing in the context of their work (Myers and Avison, 2002).

\section{Method of Data Collection}

The empirical material was collected through individual semi-structured interviews with seven purposively selected project managers that allowed us to reach data saturation (Fusch and Ness, 2015). Individual interviews were chosen since it is considered a key method in interpretive studies to gain access to participants' interpretations (Walsham, 2006) and "a very powerful data gathering technique” (Myers and Newman 2007). The semistructured approach (Myers and Newman 2007) was chosen for the interviews because it allowed us to follow up on certain questions or to clarify unexpected information. The purposive technique (Patton, 2015) for selecting the participants was based on the desired characteristics that we, the researchers, sought from the sample, i.e. the participants currently work as project managers in at least $80 \%$ of the work time, use Microsoft Teams (MS) for at least three months by active participation in two MS teams during their daily work.

Due to the presiding regulations imposed by the corona virus at the time (i.e. home office work only), interviews took place by telephone calls at times that were convenient to the participants. Audio-recording of the individual interviews was not possible due to restrictions in organizations' policy and so attempts were made to fully capture the interviews by means of writing by hand, using abbreviations and key words where necessary. Immediately after each interview the transcript was reviewed to complete the capture of full words from abbreviations and were type into a word processing software. Furthermore, Walsham (2006) states, audio-recording of the interview may also potentially limit the willingness of the participant to part with their personal most true reflections in response to the interview questions. Interviews were conducted in English since the participants regularly use the language in their work and in doing so, less information would be lost or misinterpreted by means of language translation before analysis.

\section{Method of Data Analysis}

Data analysis was performed using Lichtman's (2013) “3 C's analysis” since the research is data driven. The data analysis unfolds in six steps: extract initial coding from participants' responses to summarize ideas, revisit initial responses, develop list of categories, modify initial list by re-reading the material, revisit categories and subcategories and proceed from categories to concepts. Analysis, thus, commenced by reading the interviews in detail and then reviewing the data by assigning codes onto items of content, these were then analyzed for identification of categories, to which the coded items are assigned. The categories were then examined to determine central concepts, to which those categories may fit. In this way, the unstructured data became more structured and in an iterative fashion, the concepts were considered in context of the research aim and questions (Lichtman, 2013).

A number of ethical aspects were considered with guidance from Good Research Practice (Swedish Research Council, 2017). All participants were informed of the research purpose, outline and conditions, and were offered the chance to ask any questions prior to participation. Participants participated of free will and were invited to sign a written informed consent form to formalize the agreement of interview participation with associated data collection. The research activities have not disclosed any information about the organizations or participants. No other personal data than the name and contact details were maintained for the duration of the research, and no personal data or identifiers were recorded during the interview process. 


\section{Findings and discussion}

The data analysis process explained in previous section yielded the following six concepts.

\section{Findings}

\section{Concept 1: Changing the way of work}

Participants reflected on the way that their knowledge sharing had changed since the introduction of the technology. They noted that it has become easier to share knowledge since "a barrier has been removed for sending, so people just send you stuff. It takes ten seconds to share by link" said participant 5. Participant 7 said "you can post and don't have to think about exactly where to store it... I don't have to think who to address unless I only want one person", thus referring to the change in knowledge sharing practice, both as a disadvantage and advantage. With regards to emailing, the introduction of MS Teams was widely recognized as reducing the volume on email, being used as an option "instead of sending thousands of emails" and "reducing the number of low content emails" (participant 7). Yet it was repeatedly stated that "email is still needed" (participant 1). One participant described how new practices to use emojis had evolved to create awareness in the reach of knowledge within a team. Participant 6 states "Thumbs up means I've read that posting. Otherwise we don't know if someone read it, or it was just displayed on screen" and "I don't know when someone visualizes stuff, I can't say oh you saw that on screen" (Participant 4).

\section{Concept 2: More structure is required}

MS Teams enables storing and sharing of the files focused around events (meetings), target groups (a team or a sub-team: "channel") or within an ongoing instant-messaging conversation ("chat"). On one hand, participants rejoiced in the lack of enforced structure for storing files since "I don't have to shift around files to different people all the time" and that they can "Organize around key words and not folder structures "(participant 4), as well as "it's much easier when I'm doing multiple projects" (participant 7). Participant 3 also appreciated the support in structuring their "It helps me to have a kind of better border [between multiple, parallel projects] in my own work". However, other participants expressed frustration with repeated reference to prior technology allowing a structured approach: "it makes it super messy...I don't know where to search anything and I end up searching forever" (participant 5), "If other people set up a structure, I don't know where to find anything" (participant 3) and "I would like to have it more sorted" (participant 4).

\section{Concept 3: Facilitating knowledge sharing}

Though the participants often noted the ease of sharing knowledge, they recognized the need for commitment of other individuals in successful exchange and participant 6 summarized it with "You have to create the right setting...To convince all and be on the same page. Then people don't need any nudging to engage". Yet sometimes it was not possible, often due to (project external) stakeholders. Participant 7 described that "information is lost, because they don't know how to access it. It's as if people are not trained, or not willing to use it [MS Teams]". Participant 3 also reflected that at the start of a project "I ask which communication path they prefer and if they request email then that's what I do, because I want to keep them happy", thus resulting in duplicated work. Furthermore, several participants mentioned use of technology during handover e.g. of a project: "This is quite time consuming...the new person may have a question that was asked and answered many times, but they don't know where to find it", said Participant 3, and described that through MS Teams, a new member can be added and they are able to search the history. Participant 7 refers to the collected knowledge "You have a chronological order of all, accessible by key word search, it's always linked to documents if done well. It's easy to find documents and which documents states what [document content]".

\section{Concept 4: A need for improving user experience}

Certain aspects of using MS Teams were reported by participants as making sharing knowledge harder, such as the impact on their usual habits and this is the topic of concept 4. 4 participants referred to the concrete example of them being unable to continue using MS Teams when travelling by train (Participant 2,3,5 and 6), including to even access their data stored there, which previously were accessible offline. Participant 3 elaborated "I always need an internet connection for it. When it's gone then it doesn't work at all. So, if I'm on the train then I often can't work". Participant 5 similarly gave an example resulting problems "I had problems when working on the train ... that a document was not uploaded properly and I lost all the work. But I've adapted now and don't do that kind of work anymore on the train". 


\section{Concept 5: A need for creating strategies for knowledge continuity}

Several participants expressed that they wouldn't know how to close a team or what would happen to the contained information, despite MS Teams' being used as a main documentation approach. Participant 1 stated "If my project ends I'm not sure when or where to keep this information. If I ask now, I expect the answer will be they [decision makers or IT support] are not sure either". Similarly, participant 6 considered compliance aspects "When look at auditing aspects ...it's not clear because there are no guidelines. I expect there will be an audit in the future. They may ask to see certain documentation, but this is not possible if it was deleted some years ago". Several participants expressed a need for duplicated the stored knowledge: "I think cleaning up would be needed. I can't imagine that the chats will be useful in the long run." (Participant 2) and "If it creates technical data then we have a system for reports. We know to make sure that data is stored there" (Participant 6). Participant 7 expressed "Projects need to be documented when closed. So how do we retrieve those things... We need a solution for that, because that's how we use it. Until now we don't have that solution." Also regarding the use of the chats, Participant 1 expressed that "I don't use the instant chat [because] everything is saved and I'm not sure if one can delete parts of it. In the past there was a company policy that we shouldn't save all informal conversations".

\section{Concept 6: Need for support of individuals in their use}

The participants had not taken part of any training and had instead learned by doing through experimentation as they extended their use. Participant 1 phrased this as "I have learnt on my own...But I want to learn from my colleagues more about examples of good use, what works and how and how to manage those teams". Though equally, Participant 4 said that "In principle there is something [a training] available. I like to learn on the job. I exchange with a colleague". In contrast, Participant 1 said "I miss more training, what is possible. Or guidelines about what should be [saved] in [MS Teams] or should not". No participant was aware of any general guidelines, but participant 3 said "in our team we talked about how to exchange information" and participant 5 "I also thought about guidelines in the past. Like how to treat other people. Teams groups can get very large and it's very important to communicate in a respectful manner". Participant 7 reflected further: "The concerning part is, technical stability, where is the data stored. How safe is it, in terms of who else [administrative persons, IT support] can see it, who is not from the company... I always have some concerns, so I have core data I keep within my hard drive." Participant 6 summarized the concern for project and work continuity as "The more I use it, the more concern I have, if it crashes".

\section{Discussion}

In further consideration of the findings, they were assessed in context of prior work as deemed relevant to knowledge sharing and project management outlined in the literature and theoretical framework. Knowledge sharing is dependent on knowledge first being a) externalized i.e. spoken, written, drawn, b) made available for others i.e. in a call, file, chat comment, picture file, so that they can c) interpret and internalize this knowledge. In this perspective, MS Teams can be considered both a "communication and discourse system" as well as a "knowledge repository system", both considered to facilitate knowledge sharing (Massey and Montoya-Weiss, 2006). Participants largely recognized that the technology brought value to their knowledge sharing activities and use it on a daily basis.

In consideration of knowledge generation according to the SECI process, it could be construed that MS Teams is part of the shared context required for sharing knowledge referred to as " $b a$ " (Ichijō and Nonaka, 2007). Furthermore, different aspects of that knowledge creating process is affected by the use of MS Teams: the practice of how knowledge is generated as well as what drives the generation and sharing of knowledge. In accordance with prior research, MS Teams seems to support the sharing of tacit knowledge as well (Faraj et al., 2016) and regarding crowdsourcing ideas (Wakefield and Wakefield, 2016), MS Teams was identified as a means to quickly get input on new ideas or to guide parts of an ideation workflow. Similarly to Krancher, Dibbern and Meyer (2018) who noted a benefit from increased awareness in remote teams that rely heavily on technology, the findings indicate that project managers can similarly benefit (Wells and Kloppenborg, 2015). Here many knowledge sharing activities employ technology and significantly, MS Teams. Yet, the lack of offline functionality to access or prepare specific externalized knowledge remains a drawback and solutions are currently possible by workarounds only. However, despite the need to capture the knowledge of a project past closure (Mueller, 2015), this is currently not possible in the current set up. So when viewing projects as "generators of knowledge" and wishing to minimize duplicated work, i.e. redundancy (Wiewiora et al., 2014), these aspects were not wholly supported in the current set up. Guidelines can support individuals in their technology use to avoid persistent use with legacy technology (Stray et al., 2019) and this research supports this notion. Some participants preferred using prior technology despite knowing it would not be available soon and even avoided certain functionalities (e.g. the chat) of MS Teams due to lack of guidelines, confidence and/or proficiency. 
Furthermore, considering the research problem in context of the informatics domain model from Beynon-Davies (2013) to understand how a technology can support knowledge sharing by project managers operating within an organization (Figure 1).

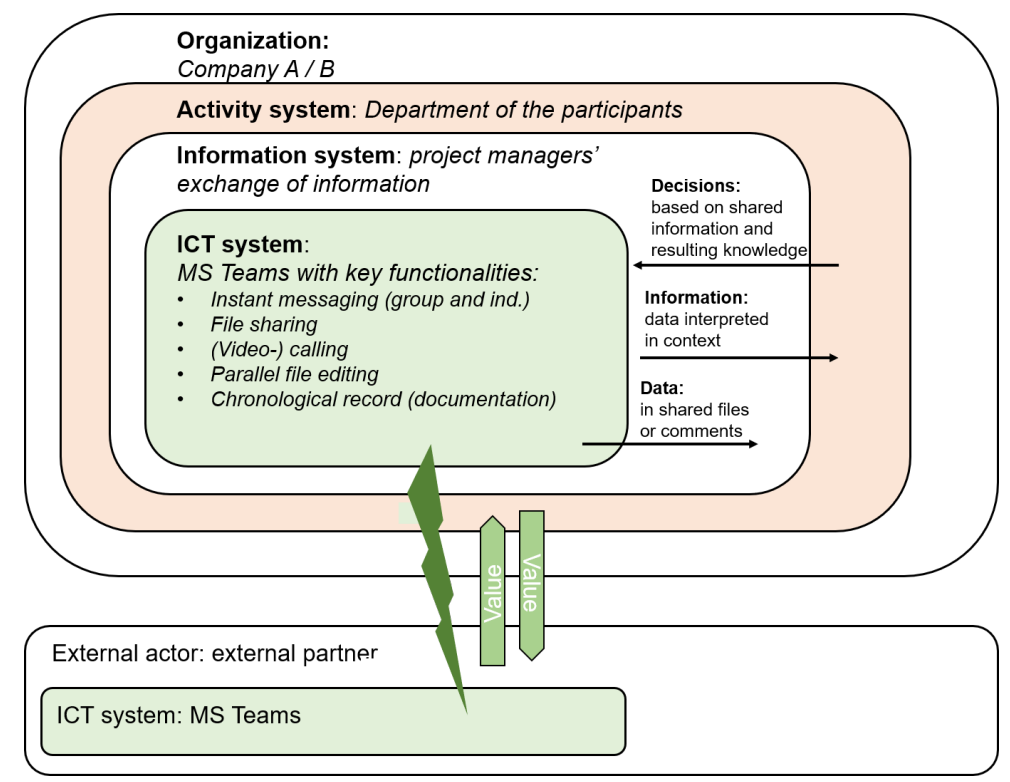

Figure 1. Consideration of findings in context of the Information System Domain Model (adopted and modified from Beynon-Davies, 2009)

The organizations of the participants make up the key context of the information system, which is in turn made up of a "series of interdependent activity systems" (Beynon-Davies, 2013, p.7). Project managers in the activity systems rely upon an information system: "to coordinate members' actions" (Beynon-Davies, 2013, p.7). The information from a system allows individuals, e.g. project managers, to decide on actions that direct the course of a project. In turn, the information consists of data, e.g. project context specific data such as cost items, consisting of symbols to represent something, e.g. 20 which in this context could mean 20 hours. The data are supplied by the information communication technology system, e.g. an effort reporting system, used to monitor the time one team member has worked. The technology itself has been defined as "an organized set of artefacts for doing things" (Beynon-Davies, 2009): a set of tools that can be used by individuals to do a task. Here, the project manager uses the information to decide on actions depending on whether the effort (hours worked) is according to plan. The ICT system consists of hardware, software, data and communication technology (Beynon-Davies, 2013) and the term is used for any technology that is used for data gathering, processing, distribution and use (Beynon-Davies, 2013).

The standard functionality offered by MS Teams, also detailed in figure 1, largely corresponds to the most relevant functionalities of technology important for project management (Gomes, Oliveira and Chaves, 2018) also indicating that MS Teams suffices as a technology supporting project management. However, the informatics domain model (Beynon-Davies, 2013) could be considered simplistic in its representation, as to not sufficiently enough reflect the complexities in how large organizations operate today. Clearly, large organizations are vastly more intricate making it more difficult to depict a detailed overview to model the decision-making process. Yet, the model serves as a starting point to discuss and illustrate the environment in which project managers operate, the role of technology in their doing so and the flows of knowledge required for their and higher management's decision making.

Thus, from the exploration and interpretation of the participants' responses to further understand how technology supports their knowledge sharing, it was seen that many aspects of knowledge sharing have been affected by the introduction of a new technology, which are elaborated further in the following conclusion.

\section{Conclusion}

This paper has presented project managers' perceptions regarding their knowledge sharing and how this is supported by the specific technology of MS Teams. To explore and interpret how a technology supports project managers' knowledge sharing, an interpretive qualitative research was conducted which collected empirical data 
through individual semi-structured interviews from seven purposively selected project managers of two large matrix organizations in Germany. The empirical material was analyzed using Lichtman's (2013) 3 C's analysis, which led to the generation of six concepts from which numerous findings in evidence of the research questions were extracted. The findings of the data driven research were further discussed with the help of informatics domain model from Beynon-Davies (2013) showing that the research setting and the activities examined use of a technology to support knowledge sharing, can be seen as an information system according to the model. The findings show that knowledge sharing technology supports the majority of knowledge sharing activities that are required for project managers to steer their projects.

The research sought to gain understanding in how MS Teams is used by project managers in their work of sharing knowledge, i.e. how a technology is used to share knowledge, and so the work contributes to existing theory of informatics focusing on technology that supports the work of project managers. The work may also aid practitioners in informatics and project management domain as the learnings may complement existing understanding on how technology should be developed or introduced into the workplace. The research findings also contribute to project managers and managers by providing a deeper understanding of opportunities and common pitfalls in use of such technology, and equally in this regard, supporting generation of guidelines for this purpose.

The research could be extended in the future by including additional sources of data as a complement, such as observations in the work place of a particular team, assessing the use of the technology through guided walkthroughs of the technology and its typical uses, as well as conducting a follow-up group interview to discuss and further understand the central findings of this work. Potential future extensions of the research could be to distill the findings into a set of hypotheses and to assess their validity in a quantitative approach involving a large number of participants. Naturally, the interpretations and conclusions derived from this work is likely to be highly dependent on this research setting, the participants and their backgrounds, their culture from a nationality perspective as well as organizational culture. Therefore, it would be of interest to research the assessments in complementary settings.

Acknowledgments. We would like to thank Professor Anita Mirijamdotter and Associate Professor Päivi Jokela for their constructive feedback. Many thanks to the research participants, the project managers of the two organizations in Germany, who willingly participated in the process of data collection. Thank you reviewers for your helpful comments.

\section{References}

APM, 2020. Association for Project Management - the chartered body for the project profession. [online] Available at: $<$ https://www.apm.org.uk/about-us/> [Accessed 9 Feb. 2020].

Bansler, J.P. and Havn, E., 2006. Sensemaking in technology-use mediation: Adapting groupware technology in organizations. Computer Supported Cooperative Work, 15(1), pp.55-91. https://doi.org/10.1007/s10606005-9012-x

Beynon-Davies, P., 2013. Business Information Systems. 2nd ed. New York: Palgrave Macmillan.

Bredillet, C.N., 2014. Agile project management essentials from the Project Management Journal. Software Project Management in a Changing World. Hoboken: John Wiley \& Sons.

Faraj, S., von Krogh, G., Monteiro, E. and Lakhani, K.R., 2016. Online community as space for knowledge flows. Information Systems Research, 27(4), pp.668-684. https://doi.org/10.1287/isre.2016.0682

Fuentes-Ardeo, L., Otegi-Olaso, J.R. and Aguilar-Fernandez, M.E., 2017. How the project knowledge management and the sustainability in project management affect the project success. In: IEEE (Institute of Electrical and Electronics Engineers), 9th International Conference on Intelligent Data Acquisition and Advanced Computing Systems: Technology and Applications, IDAACS 2017. Bucharest, Romania. 21-23 Sept. 2017. New York: IEEE Press.

Ghobadi, S. and Mathiassen, L., 2016. Perceived barriers to effective knowledge sharing in agile software teams. Information Systems Journal, 26(2), pp.95-125. https://doi.org/10.1111/isj.12053

Gomes, F., Oliveira, M. and Chaves, M.S., 2018. An analysis of the relationship between knowledge sharing and the project management process groups. Knowledge and Process Management, 25(3), pp.168-179. An analysis of the relationship between knowledge sharing and the project management process groups. https://doi.org/10.1002/kpm.1578

Hesse-Biber, S. and Johnson, R. eds., 2015. Oxford Handbook of Multimethod and Mixed Methods Research Inquiry. Oxford: Oxford University Press.

Ichijō, K. and Nonaka, I., 2007. Knowledge creation and management new challenges for managers. Oxford; New York: Oxford University Press.

IPMA, 2020. IPMA: About Us. [online] Available at: <https://www.ipma.world/about-us/> [Accessed 9 Feb. 2020]. 
Kauffmann, D. and Carmi, G., 2014. How team leaders can use ICT to improve trust among virtual teams to increase collaboration? International Journal of Engineering and Innovative Technology, 3(9), pp. 204-220.

Klein, H.K. and Myers, M.D., 1999. A set of principles for conducting and evaluating interpretive field studies in information systems. MIS Quarterly: Management Information Systems, 23(1), pp.67-94. https://doi.org/10.2307/249410

Kogon, K., Blakemore, S. and Wood, J., 2015. Project Management for the Unofficial Project Manager. Dallas: BenBella Books.

Krancher, O., Dibbern, J. and Meyer, P., 2018. How social media-enabled communication awareness enhances project team performance. Journal of the Association for Information Systems, 19(9), pp.813-856.

Lichtman, M., 2013. Making Meaning From Your Data. Qualitative Research in Education, pp.241-268.

Massey, A.P. and Montoya-Weiss, M.M., 2006. Unraveling the Temporal Fabric of Knowledge Conversion: A Model of Media Selection and Use. MIS Quarterly, 30(1), pp.99-114. https://doi.org/10.2307/25148719

McLure Wasko, M. and Faraj, S., 2000. 'It is what one does': Why people participate and help others in electronic communities of practice. Journal of Strategic Information Systems, 9(2-3), pp.155-173. https://doi.org/10.1016/S0963-8687(00)00045-7

van der Meulen, N., van Baalen, P., van Heck, E. and Mülder, S., 2019. No teleworker is an island: The impact of temporal and spatial separation along with media use on knowledge sharing networks. Journal of Information Technology, 34(3), pp.243-262. https://doi.org/10.1177/0268396218816531

Microsoft, 2019. Microsoft Teams - Meet the hub for teamwork in Office 365. [online] Available at: $<$ https://products.office.com/en-us/microsoft-teams/group-chat-software $>$ [Accessed 27 Jan. 2020].

Microsoft, 2020. Office 365 suite features. [online] Available at: <https://docs.microsoft.com/enus/office365/servicedescriptions/office-365-platform-service-description/office-365-suite-features> [Accessed 20 Feb. 2020].

Morris, P., 2013. Reconstructing Project Management. 1st ed. Hoboken: John Wiley \& Sons.

Mueller, J., 2015. Formal and informal practices of knowledge sharing between project teams and enacted cultural characteristics. Project Management Journal, 46(1), pp.53-68. https://doi.org/10.1002/pmj.21471

Myers, M.D. and Avison, D., 2002. Qualitative research in information systems. Thousand Oaks, CA: Sage.

Myers, M.D. and Newman, M., 2007. The qualitative interview in IS research: Examining the craft. Information and Organization, 17(1), pp.2-26. https://doi.org/10.1016/j.infoandorg.2006.11.001

Olaniran, O.J., 2017. Barriers to Tacit Knowledge Sharing in Geographically Dispersed Project Teams in Oil and Gas Projects. Project Management Journal, 48(3), pp.41-57. https://doi.org/10.1177/875697281704800303

Patton, M.Q., 2015. Qualitative evaluation and research methods. 4th ed. Newbury Park, CA: Sage.

Petter, S., Delone, W. and McLean, E.R., 2012. The past, present, and future of 'IS success'. Journal of the Association for Information Systems, 13(5), pp.341-362. https://doi.org/10.17705/1 jais.00296

PMI, 2020. In a business world of constant change and disruption, project, program and portfolio management are the bridges that connect strategy to implementation. Pulse of the Profession Thought Leadership. [online] Available at: <https://www.pmi.org/learning/thought-leadership > [Accessed 2 Feb. 2020].

Polanyi, M., 1966. The Logic of Tacit Inference. Philosophy, 41(155), pp.1-18.

PRINCE2, 2020. What is PRINCE2? [online] Available at: <https://www.prince2.com/eur/what-is-prince2> [Accessed 9 Feb. 2020].

Project Management Institute, 2013. A guide to the project management body of knowledge (PMBOK®). Newtown Square: Project Management Institute.

Stray, V., Moe, N.B. and Noroozi, M., 2019. Slack Me if You Can! Using Enterprise Social Networking Tools in Virtual Agile Teams. In: ACM/IEEE, 14th International Conference on Global Software Engineering, ICGSE 2019. Montreal Canada, 24-26 May 2019. New York: IEEE Press. https://doi.org/10.1109/ICGSE.2019.00031

Swedish Research Council, 2017. Good Research Practice. [online] Available at: $<$ https://www.vr.se/download/18.5639980c162791bbfe697882/1555334908942/Good-ResearchPractice_VR_2017.pdf> [Accessed 7 Feb. 2020].

Wakefield, R. and Wakefield, K., 2016. Social media network behavior: A study of user passion and affect. Journal of Strategic Information Systems, [online] 25(2), pp.140-156. Available at: http://doi.org/10.1016/j.jsis.2016.04.001

Walsham, G., 1993. Interpreting information systems in organizations. Chichester, UK: Wiley.

Walsham, G., 2006. Doing interpretive research. European Journal of Information Systems, 15(3), pp.320-330. https://doi.org/10.1057/palgrave.ejis.3000589

Wells, K. and Kloppenborg, T., 2015. Project Management Essentials. New York: Business Expert Press.

Wiewiora, A., Murphy, G., Trigunarsyah, B. and Brown, K., 2014. Interactions between organizational culture, trustworthiness, and mechanisms for inter-project knowledge sharing. Project Management Journal, 45(2), pp.48-65. https://doi.org/10.1002/pmj.21407

Wolf and Blomberg, 2020. Making Sense of Enterprise Apps in Everyday Work Practices. Computer Supported Cooperative Work, 29(1-2), pp.1-27. https://doi.org/10.1007/s10606-019-09363-y 